\title{
Model-founded explorations of the roles of molecular layer inhibition in regulating Purkinje cell responses in cerebellar cortex: more trouble for the beam hypothesis
}

\author{
James M. Bower* \\ Research Imaging Center, University of Texas Health Science Center, San Antonio, TX, USA
}

Edited by:

Egidio D'Angelo, University of Pavia, Italy

\section{Reviewed by:}

Yosef Yarom, Hebrew University, Israel Michael Hausser, University College London, UK

${ }^{*}$ Correspondence:

James M. Bower, Research Imaging Center, 7703 Floyd Curl Drive, San

Antonio, TX 78229-3900, USA

e-mail:bower@uthscsa.edu
For most of the last 50 years, the functional interpretation for inhibition in cerebellar cortical circuitry has been dominated by the relatively simple notion that excitatory and inhibitory dendritic inputs sum, and if that sum crosses threshold at the soma the Purkinje cell generates an action potential. Thus, inhibition has traditionally been relegated to a role of sculpting, restricting, or blocking excitation. At the level of networks, this relatively simply notion is manifest in mechanisms like "surround inhibition" which is purported to "shape" or "tune" excitatory neuronal responses. In the cerebellum, where all cell types except one (the granule cell) are inhibitory, these assumptions regarding the role of inhibition continue to dominate. Based on our recent series of modeling and experimental studies, we now suspect that inhibition may play a much more complex, subtle, and central role in the physiological and functional organization of cerebellar cortex. This paper outlines how model-based studies are changing our thinking about the role of feed-forward molecular layer inhibition in the cerebellar cortex. The results not only have important implications for continuing efforts to understand what the cerebellum computes, but might also reveal important features of the evolution of this large and quintessentially vertebrate brain structure.

Keywords: modeling, evolution

\section{THE CLASSICAL VIEW OF CEREBELLAR MOLECULAR LAYER INHIBITION}

For most of the last 50 years, the functional interpretation of cerebellar inhibitory circuits in general, and molecular layer inhibition in particular, has been dominated by the relatively straight forward hypothesis that inhibitory and excitatory synaptic inputs sum spatially and temporally to determine whether Purkinje cells reach threshold and consequently generate an action potential (Andersen, 2006). This "integrate and fire" framework continues to provide the basis for most models and theories of cerebellar function today (Medina and Mauk, 2000; Mauk and Ohyama, 2004; Carrillo et al., 2008; Dean et al., 2010), and in fact for the role of inhibition in brain function as a whole (Andersen, 2006). Consistent with the traditional integrate and fire model of neuronal function, the role of inhibition in the cerebellum has traditionally been described in terms of "sculpting," blocking, or canceling excitatory effects on neuronal output (Bell and Grimm, 1969; Andersen, 2006; Gao et al., 2006; Shin and De Schutter, 2006; McKay et al., 2007; de Gruijl et al., 2009; Wisden et al., 2009; Wulff et al., 2009; Dean et al., 2010), a role that was originally codified in what has come to be known as "the cerebellar beam hypothesis" (Eccles et al., 1967). Originally proposed by Braitenberg and Atwood (1958) based on the unique geometrical relationship between the parallel fibers of the granule cells and the Purkinje cell, the beam hypothesis holds that computation in cerebellar cortical circuitry is fundamentally organized around the propagation of excitatory parallel fiber activity along "beams," sequentially activating cerebellar Purkinje cells (Eccles et al., 1967; Heck et al., 2007). Molecular layer inhibition was assumed to sculpt and sharpen these excitatory “on-beam" Purkinje cell responses by producing an "off-beam" inhibitory area transversely flanking each side of the core beam (Cohen and Yarom, 2000; Gao et al., 2006; Heck et al., 2007; Rokni et al., 2007, 2009).

\section{ARE THERE NATURALLY OCCURRING PARALLEL FIBER INDUCED PURKINJE CELL BEAMS?}

While the assumption of strong parallel fiber inputs on Purkinje cells and inhibition as a sculpting lateral mechanism continues to dominate modern cerebellar theories (Mauk and Ohyama, 2004; Hong and Optican, 2008), there is actually little experimental evidence that natural patterns of afferent cortical activation actually produce beam-like patterns of either excited or inhibited Purkinje cells (Bell and Grimm, 1969; Eccles et al., 1972; Bower and Woolston, 1983; Kolb et al., 1997; Cohen and Yarom, 1998; De Jaeger and Proteau, 2003; Holtzman et al., 2006; Heck et al., 2007; Rokni et al., 2007; de Solages et al., 2008). Instead Purkinje cells either activated or inhibited by peripheral stimuli are found in patches, not beams (Eccles et al., 1972; Bower and Woolston, 1983; Gao et al., 2006) whose locations, when measured, are found to be in close proximity to activated regions of the granule cell layer (Bower and Woolston, 1983; Kolb et al., 1997; Cohen and Yarom, 1998; De Jaeger and Proteau, 2003; Lu et al., 2005; Rokni et al., 2007; Brown and Ariel, 2009). Those few in vivo reports claiming to demonstrate the presence of beams either mapped Purkinje cell responses without reference to activity in the granule cell layer (Garwicz and Andersson, 1992; Jorntell and Ekerot, 2002; Heck et al., 2007), employed electrical rather than natural forms 
of afferent stimulation (Jorntell and Ekerot, 2002), or drew their conclusions based on patterns of activity obtained in completely different animals (Jorntell and Ekerot, 2002, 2006). For additional discussion of these methodological concerns see Bower (2002).

Figure 1, reproduced from Bower and Woolston, 1983, shows the pattern of Purkinje cell excitatory and inhibitory activity induced in cerebellar folium Crus IIA following stimulation of the ipsilateral upper lip in an anesthetized rat. Figure 1A shows the spatial distribution of granule cell layer activity induced by the peripheral tactile stimulus, while Figure $1 \mathbf{B}$ shows the resulting activity produced in Purkinje cells. It can be seen that those Purkinje cells responding with short-latency increases in spike output (indicated by black histogram bins in Figure 1B) were not found along beams, but instead were restricted to the region directly overlying the activated granule cell layer (dotted area in both Figures 1A,B). Similarly, Purkinje cells showing a reduction in firing were also not found along a beam, but instead were located above as well as adjacent to the activated region of the granule cell layer (stippled histogram bins in Figure 1B). While this apparent inhibitory influence does extend slightly beyond the activated region of the granule cell layer, at no point were reductions in Purkinje cell firing seen at a distance greater than 200 microns, even though parallel fibers in the rat can extend for up to a $2.5 \mathrm{~mm}$ in both directions from the site of granule cell layer activation (Houk and Walsh, 1971; Harvey and Napper, 1991; Barmack and Yakhnitsa, 2008a). In other words, just as there was no "beam" of activated Purkinje cells extending
A

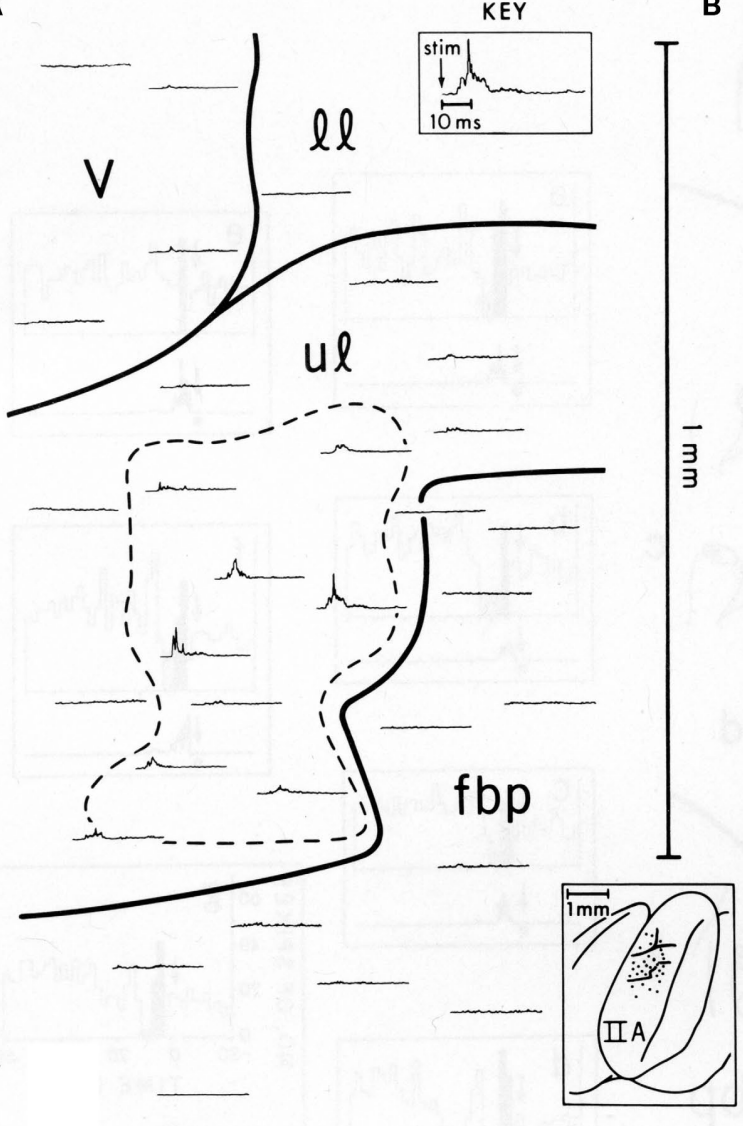

GC LAYER EVOKED RESPONSE MAP

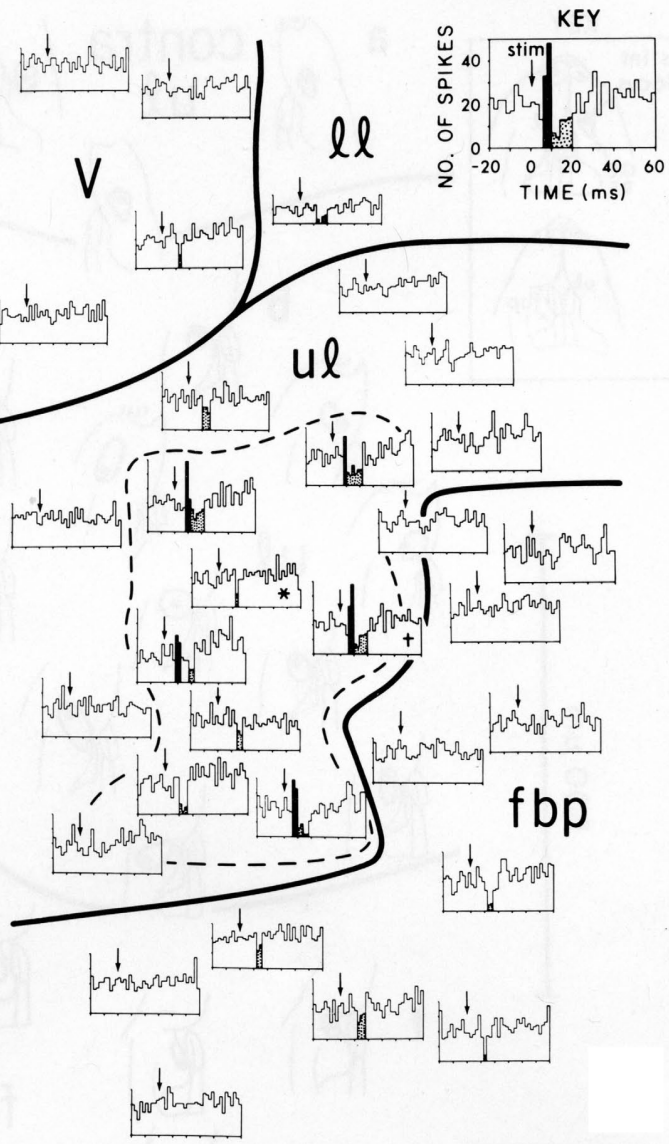

PC LAYER EVOKED RESPONSE MAP
FIGURE 1 | Comparison of the spatial distribution of granule cell and Purkinje cell layer responses in Crus IIA of the rat, evoked by stimulation of a single upper lip locus. Parallel fibers run from the top of the figure (medial) to the bottom (lateral). (A) Granule cell layer evoked-response map. This map illustrates the spatial distribution of activity evoked by mechanical stimulation of the single ipsilateral upper lip locus. Each rectified, averaged GC layer response (30 trials) is centered over the electrode puncture location from which the response was recorded (see brain diagram of Crus IIA at bottom center). The largest GC layer responses were recorded within the area enclosed by the dashed line. The time scale and stimulus onset (arrow) for all traces are shown in the key at top right. (B) Purkinje cell layer evoked-response map. This map illustrates the spatial distribution of PC layer activity evoked by the same peripheral stimulus that evoked the GC layer response in (A). Each PST histogram represents responses of a different Purkinje cell recorded from the same 19 electrode punctures as the GC layer responses shown in (A). Statistically significant short-latency increases in PC activity are indicated in black with decreases stippled. Both these maps are oriented so that the course of the GC parallel fibers is from the top of the figure to the bottom, i.e., along the axis of the folium (see brain diagram at lower center). In each PST histogram, the arrow indicates the onset of the stimulus. The key at top right indicates the scale for the $x$ and $y$ axes for all histograms. v, vibrissae; 11, lower lip; ul, upper lip; fbp, furry buccal pad. 
down the folium, there is also no evidence for an "off-beam" inhibitory band extending along the parallel fibers. The original beam hypothesis also did not predict inhibitory effects within the ("onbeam”) area of Purkinje cell excitation (Eccles et al., 1967). In the data shown in Figure 1 and elsewhere (Cohen and Yarom, 2000), short duration excitatory Purkinje cell responses are almost always followed by a decrease in spiking, presumably due to inhibitory effects. It should also be noted that this decrease in firing occurs at the same latency whether preceded by excitation or not, and regardless of whether the Purkinje cell is above or adjacent to the area of granule cell layer activation.

\section{MODELING PURKINJE CELL RESPONSES TO FOCAL ACTIVATION OF THE GRANULE CELL LAYER}

Over the last several years we have constructed realistic models of cerebellar Purkinje cells (Deschutter and Bower, 1994a,b,c; Jaeger et al., 1997; Santamaria and Bower, 2005) and the cerebellar cortical network (Santamaria et al., 2007) to try to better understand, among other things, why focal activation of the granule cell layer does not produce beams of Purkinje cell excitation or inhibition. These modeling efforts were designed to test a specific hypothesis, first formulated by Llinas (1982), that the focal activation of Purkinje cells was due to synaptic input from synapses on the ascending segment of the granule cell axon before it bifurcated into two parallel fibers (Mugnaini, 1972). Llinas suggested that these ascending segment synapses had a more powerful influence on Purkinje cells because they provided a more synchronous input than did parallel fibers contacting Purkinje cells further down the folium (Llinas, 1982). Confirming the first component of this hypothesis, we have obtained direct anatomical evidence that Purkinje cells do receive excitatory synaptic projections from ascending granule cell axons (Gundappa-Sulur et al., 1999; Lu et al., 2009), and experimental evidence is mounting that these inputs drive strong excitatory responses in Purkinje cells (Jaeger and Bower, 1994, 1999; Cohen and Yarom, 1998; Gundappa-Sulur et al., 1999; Isope and Barbour, 2002; Lu et al., 2005; Sims and Hartell, 2005, 2006; Rokni et al., 2008; Brown and Ariel, 2009; Lu et al., 2009; Walter et al., 2009).

While ascending granule cell inputs likely account for Purkinje cell activation directly above an activated region of the granule cell layer, until recently, the other component of the Llinas hypothesis, that the lack of Purkinje cell responses along a beam is due to the relative desynchronization of parallel fibers has not been examined directly. However, several known anatomical and physiological features of the parallel fiber system are consistent with this proposal. First, while it has been known for some time that individual parallel fibers make one synapse per Purkinje cell (Harvey and Napper, 1991), recent evidence in mammals suggests that there may be approximately twice as many granule cell synapses per unit length on ascending as compared to parallel fiber segments of the granule cell axon (Pichitpornchai et al., 1994) a result also found in turtles (Tolbert et al., 2004). With respect to parallel fiber desynchronization, it has been known for a long time that parallel fibers are quite variable in their conduction velocities (Eccles et al., 1966). However, in addition, the structure of the molecular layer itself would seem to assure a more desynchronized parallel fiber volley down the molecular layer. Specifically, action potentials initiated in parallel fiber volley down the folium must first traverse the entire height of the molecular layer before reaching the parallel fiber branch point, while action potentials in deeper parallel fibers start propagating almost immediately (see Figure 2). Thus the geometry of the cortex itself appears to contribute to the desynchronization of parallel fibers. Interestingly, this initial desynchronization due to the branching pattern geometry of granule cell axons in the molecular layer appears to be further enhanced by the fact that the intrinsic conduction velocities of deeper parallel fibers can be twice as fast as those found more superficial in the molecular layer (Vranesic

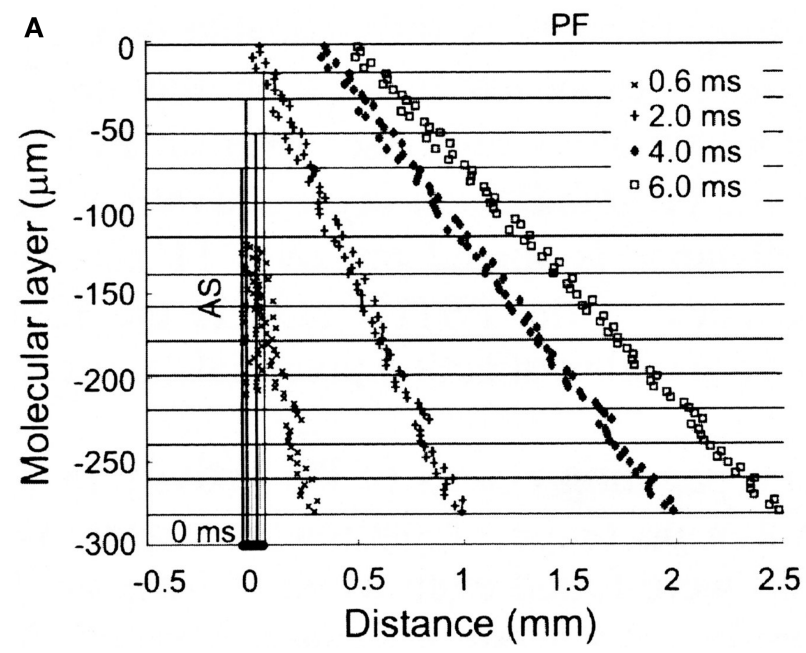

FIGURE 2 | Spatial and temporal patterns of action potential propagation along granule cell axons. (A) Calculated synaptic distributions following a synchronously activated patch of granule cells, consisting of 80 cells distributed over 50 square microns along the $X$-axis. Note the increasingly desynchronized volley of parallel fiber activity with distance from the activated region. (B) Range

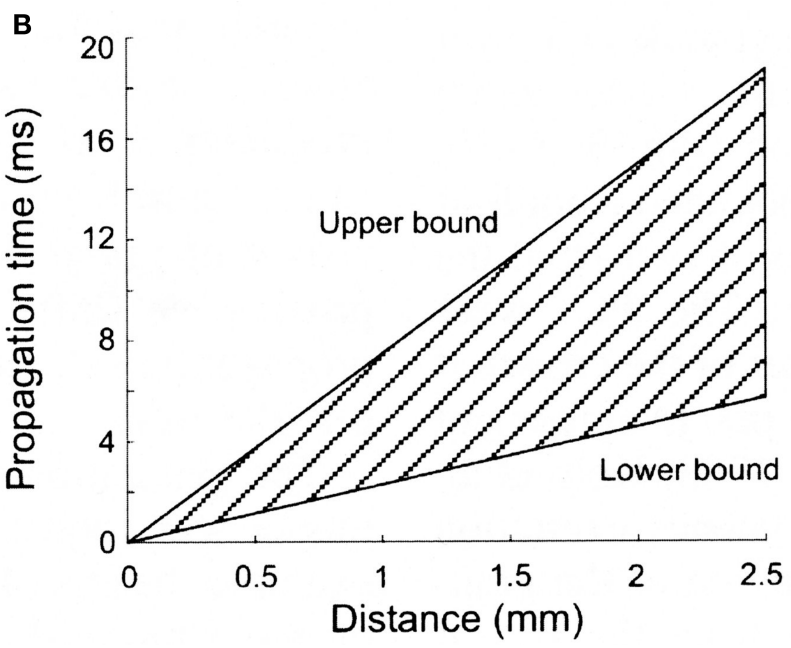

of propagation times for action potentials converging at different distances from the site of granule cell activation. The upper and lower bounds are calculated using the slowest $(0.15 \mathrm{~m} / \mathrm{s})$ and fastest $(0.50 \mathrm{~m} / \mathrm{s})$ published propagation velocities for parallel fiber action potentials. Reproduced with permission from Santamaria et al., 2007. 
et al., 1994). Figure 2 shows the predicted spatial and temporal range of parallel fiber activity following focal granule cell layer activation when these anatomical and physiological constraints are taken into account.

In order to test whether these properties of the parallel fiber system alone could account for the lack of Purkinje cell beams, we constructed a biologically realistic model of the cerebellar granule cell to Purkinje cell pathway (Santamaria et al., 2007). When the spatial and temporal patterns of parallel fiber activity shown in Figure 2 were applied to modeled Purkinje cells, the results, shown in Figure 3, were unexpected. In Figure 3, the top four histograms (A-D) are physiological data obtained in vivo following focal activation of the granule cell layer under the Purkinje cell whose response is labeled A. As in our original report (Bower and Woolston, 1983) and as shown in Figure 1, only the Purkinje cell overlying the activated region of the granule cell layer responded with short-latency excitation. The second set of histograms (E-H) were obtained when the spatial temporal pattern of granule cell inputs shown in Figure 2 were applied to Purkinje cell models positioned at the same distances from simulated granule cell activation as in A-D. Despite an intentional choice of (biologically plausible) parameters minimizing the number of parallel fiber inputs and maximizing their degree of asynchrony (see Santamaria et al., 2007 for details), the model surprisingly still produced beams of activated Purkinje cells. Thus, while the desynchronization of parallel fibers resulted in progressively broader Purkinje cell excitatory responses with distance, the model produced simulated beam-like excitatory responses not seen experimentally. Based on these modeling results we concluded that the original parallel fiber desynchronization mechanism proposed by Llinas (1982) was not sufficient to account for the experimental data.

Looking more closely at the responses shown in Figures 3A-D and Figures $3 \mathbf{E}-\mathbf{H}$, beyond the existence of beam-like activation, the most striking difference between the real and simulated results is the excessive activation of the simulated Purkinje cells. Comparing Figures $\mathbf{3 A}$ and $\mathbf{E}$ for example, it is clear that stimulation in the model produced a much more dramatic and prolonged excitatory response than is seen in vivo. Accordingly, it seemed likely that more realistic responses would likely be obtained after adding molecular layer inhibition which had not to that point been included in the model. When molecular layer inhibition was added to the network model (Santamaria et al., 2007), while changing no other model parameters, the simulated responses (Figures 3I-L) were remarkably similar to those recorded in vivo (Figures 3A-D). For example, after adding molecular layer inhibition, Purkinje cell responses above the activated region of the granule cell layer included both excitatory and following inhibitory responses (Figure 3I), while Purkinje cells not directly overlying the activated granule cell layer but nearby showed decreases in spiking (Figure 3J). Further, and importantly, the beam-like activity recorded in the model without inhibition (Figures 3F-H) was completely absent.

\section{MOLECULAR LAYER INHIBITION SUPPRESSES THE BEAM}

The most general prediction of the modeling effort just described is that feed-forward molecular layer inhibition plays a critical, but here-to-fore unrecognized role in regulating the responses of Purkinje cells to excitatory granule cell input, an in particular in suppressing the "beam." Instead of laterally sculpting excitatory Purkinje cell beams as predicted by the beam hypothesis and assumed in many models and interpretations of cerebellar cortical function (Bell and Grimm, 1969; Mauk and Ohyama, 2004; Gao et al., 2006; Shin and De Schutter, 2006; Steuber et al., 2007; Hong and Optican, 2008), molecular layer inhibition instead appears to prevent excitatory Purkinje cell beams from occurring. In support of this basic model prediction, we subsequently showed experimentally that blocking molecular layer inhibition in vivo, results in the emergence of beam-like patterns of Purkinje cell activity that are remarkably similar to those seen in the model lacking feed-forward molecular layer inhibition (Santamaria et al., 2007). A similar result has recently been reported by Walter et al. (2009).

While the reader is referred to Santamaria et al. (2007), for a full description of the network modeling parameters, responses to parameter variations, and other specific model-based explanations for the influence of molecular layer interneurons, there are several aspects of the modeling results that are worthy of specific mention here. As with many realistic modeling efforts (Bower, 1990), one of the most valuable contributions this type of model can make is in shedding new light on the functional consequences of well known anatomical features. Through most of the history of neuroscience, function has simply been inferred from a fairly straightforward interpretation of the anatomy, the beam hypothesis itself being an excellent example. Accordingly, the most obvious interpretation of the anatomical arrangement between parallel fibers and Purkinje cells has been that parallel fiber activity would result in a successive spatial activation of Purkinje cells, an interpretation bolstered by experimental studies using direct electrical stimulation techniques (Eccles et al., 1966), essentially designed on the assumption that this was how the system worked. It has taken careful experimental investigations using natural peripheral stimuli (Bower and Woolston, 1983; Santamaria et al., 2007), combined with realistic modeling, to understand why this is not the case. Similarly, the laterally inhibitory role for molecular layer interneurons in the beam hypothesis derives from a simple interpretation of the fact that the axons of these neurons course in a direction perpendicular to the parallel fibers (Sultan and Bower, 1998). Considering the anatomy alone, it seems perfectly rational to assume simple lateral inhibitory effects, while it has never been previously proposed that laterally projecting axons would counterbalance progressive parallel fiber excitation down the folium. The model however, demonstrates such counterbalancing as a consequence of a combination of the relatively rapid induction of inhibitory inputs, the desynchronization of parallel fiber volleys, and the intrinsic electrical properties of the Purkinje cell dendrite. None of these dynamic effects can be inferred from looking at the anatomy of axonal projections alone.

Never-the-less, the anatomical fact that molecular layer axons project perpendicular to the course of the parallel fibers (Sultan and Bower, 1998), almost certainly has some functional significance. In the context of the counterbalancing role for molecular layer inhibition, this perpendicular project pattern could be interpreted as suggesting that there is a close relationship between the specific parallel fibers synapses made on a particular Purkinje cell dendritic tree and the feed-forward inhibitory synapses projecting onto that same tree. Further anatomical studies would be necessary to confirm the possibility, but it would be entirely consistent with the counterbalancing effect of inhibition proposed here if the same parallel fibers synapsing on a particular Purkinje cell, also activated nearby molecular layer interneurons whose orthogonal 


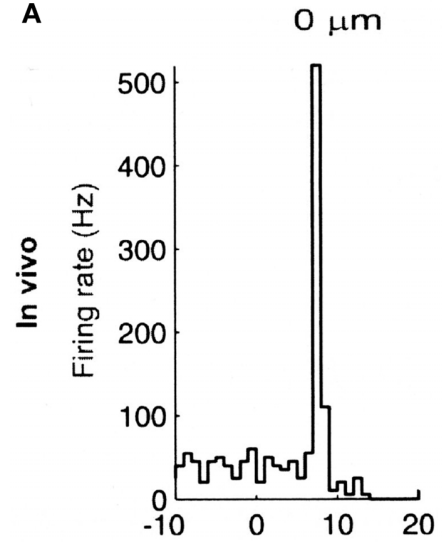

E

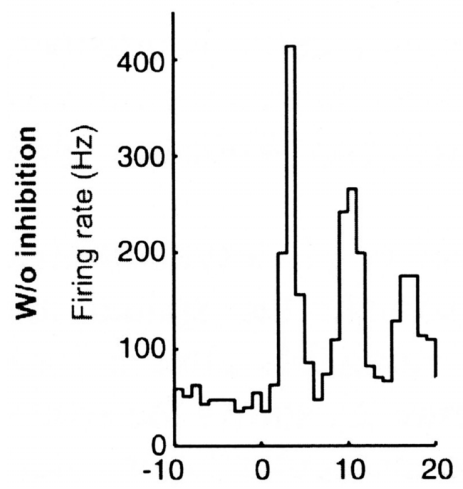

B $\quad 380 \mu \mathrm{m}$

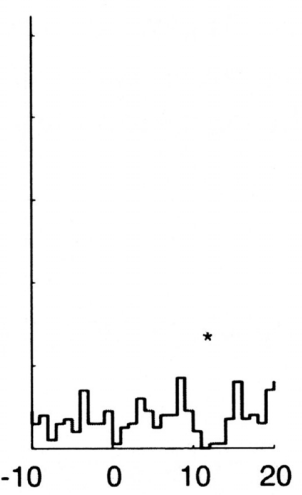

$\mathbf{F}$

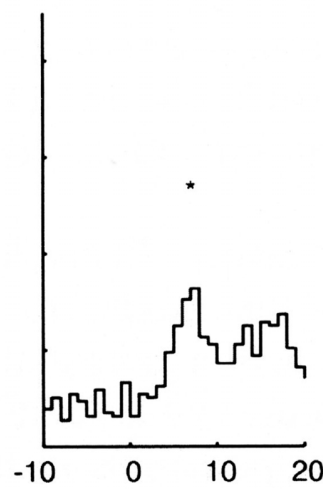

$\mathbf{J}$

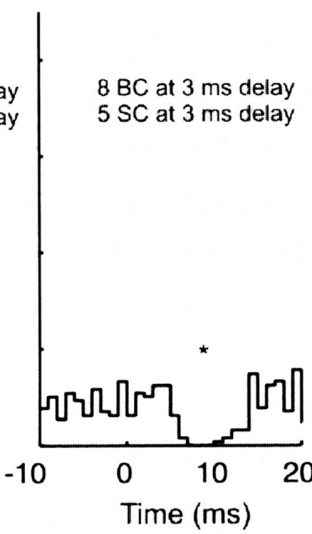

C $\quad 760 \mu \mathrm{m}$

D $1190 \mu \mathrm{m}$
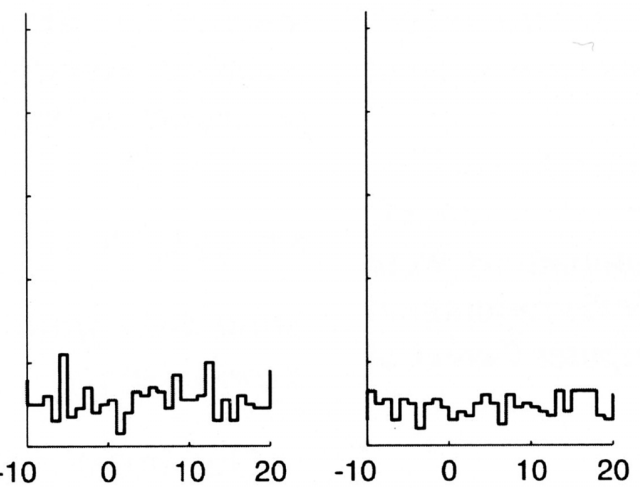

G

H
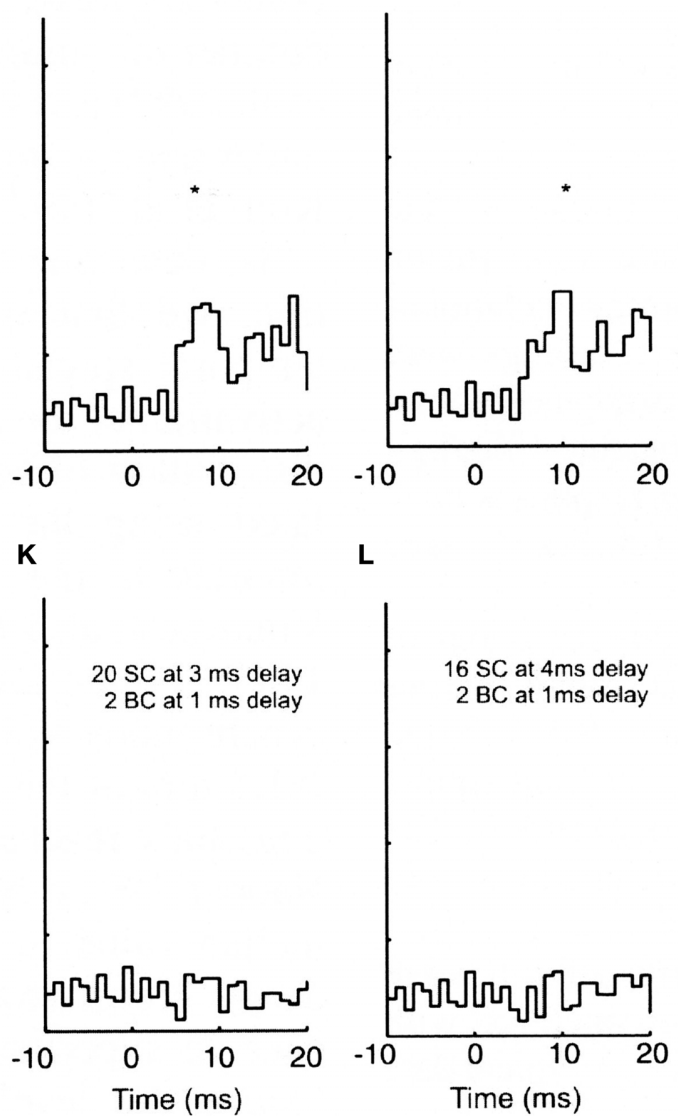

$\mathbf{L}$

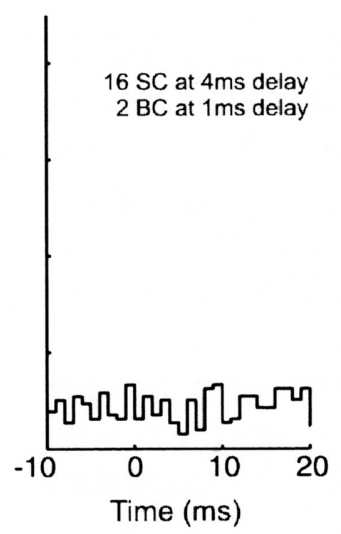

FIGURE 3 | Experimental and modeled granule cell effects on PCs. (A-D) PSTHs (300 trials) of simultaneously recorded PCs evoked by tactile stimulation of the ipsilateral upper lip in vivo. (A) PC immediately above the stimulated region of granule cells. (B-D) PCs recorded along the path of the parallel fibers at the indicated distances. (E-H) PSTHs (256 trials) from network simulations using the largest range of parallel fiber conduction velocities $(0.15 \mathrm{top}, 0.5 \mathrm{~m} / \mathrm{s}$ bottom), and $4 \%$ of granule cells activated. (I-L) Similar simulations as (E-H) with feed-forward inhibition added to the model. (E) and (I) received the same total amount of excitatory input, split between ascending and parallel fiber synapses. The notations indicate the inhibitory conduction delays as well as the number of basket (BC) and stellate cell (SC) synapses converging on the corresponding PCs. All simulated Purkinje cells received randomly activated excitatory and inhibitory synapses resulting in an average spontaneous firing frequency of $40 \mathrm{~Hz}$. The difference in the delay in the excitatory onset latency in the in vivo (A) and modeled ( $\mathbf{E}$ and $\mathbf{I})$ PCs is due to the additional conduction delays from the stimulated skin to the cerebellum in vivo, which for simplicity were not included in the model. The * denotes statistically significant difference from background activity (T-test, $p<0.05)$. Reproduced with permission from Santamaria et al., 2007. axonal project patterns assured a restricted influence on the same Purkinje cell. The project patterns of molecular layer interneurons also suggest that the dynamical state of the dendrite of parasag- gital rows of Purkinje cells might also be coordinated, perhaps reflecting the known parasaggital orientation of projections to the deep cerebellar nuclei (Ruigrok, 2010). Whatever the functional 
significance of the branching pattern of inhibitory axons, for certain their effects are more complex than the simple flanking inhibition assumed by the beam hypothesis.

While our (Santamaria et al., 2007) and Walter's et al. (2009) in vivo studies provide experimental support for the general role of inhibition in suppressing Purkinje cell beams, a recent report by Yarom based on an in vitro whole cerebellar preparation purports to find no evidence for such an inhibitory effect (Rokni et al., 2007, 2008). While these authors do interpret their data to suggest that granule cell input does not produce beams, they report no additional lateral spread of Purkinje cell activity after the topical application of agents that block inhibition (Rokni et al., 2007, 2008). There are several possible explanations for the failure to see, in this preparation, the emergence of beam-like activity we and others have reported after blocking inhibition in vivo (Santamaria et al., 2007; Walter et al., 2009). As these authors acknowledge, the interpretation of optical recordings can be difficult, with optical signals likely dominated by dendritic processes, with little contribution from the somatic spike. This is especially the case in Purkinje cells where somatic spikes do not propagate into the dendrite (Llinas and Sugimori, 1980). This is also a concern with the recent report on the effects of cortical inhibition by Gao et al., 2006. Therefore, it seems likely that the optical imaging methods used in these studies would not detect changes in somatic Purkinje cell spiking and therefore would not necessarily be expected to reveal the beam-like behavior recorded at the single cell level when inhibition is blocked (Santamaria et al., 2007; Walter et al., 2009). That said, it should be noted that a close inspection of the published data (Figure 6, Rokni et al., 2007) does appear to demonstrate a subtle increased spreading of activity along the direction of the parallel fibers when inhibition is blocked, possibly including a region (to the right of the figure) outside the optically sampled area.

A second concern about the optical imaging data involves the likely plane of section being sampled. In our modeling results, most of the change in dendritic currents associated with blocking inhibition were localized in the bottom third of the molecular layer. If the optical imaging results principally reflect activity in upper levels, then they might be transparent to the results we report. It should be noted that even in the presence of inhibition, our network model indicates robust synaptic effects in Purkinje cells along the parallel fibers (Figure 4B) which never-the-less do not result in Purkinje cell somatic firing (Figure 4G).

Finally, if the lack of parallel fiber induced beams is not a consequence of the molecular layer inhibitory circuitry, one is left to argue that there is some fundamental difference in the strength of synaptic effects between ascending and parallel fiber synapses (c.f. Rokni et al., 2007, 2008). While there is evidence for morphological and physiological differences in the plastic properties of these synapses (Gundappa-Sulur et al., 1999; Sims and Hartell, 2005, 2006), there is good evidence that these synapses don't differ in their average synaptic strength (Isope and Barbour, 2002; Walter et al., 2009). It should be noted that, the synaptic strengths of parallel fiber and ascending segment inputs in our models were the same. Therefore, an equally important prediction of the modeling results is that functional differences between ascending and parallel fiber synapses are NOT based on differences in their average synaptic strengths, but instead on the temporal organization of cortical patterns of synaptic activity and in particular the relative timing of inhibition. Thus, while Walter et al., 2009, have interpreted the similarity in synaptic strengths between parallel fiber and ascending segment synapses to suggest a "computationally equivalence," computational significance is determined by the circuitry in which synapses are embedded. In other words, the influence of both types of synapses on Purkinje cell behavior is strongly influenced by the larger dynamical structure of the network in which the Purkinje cell is embedded. It should also be noted that the claim of computational equivalence by Walter et al. (2009), would seem to depend on some mechanism to globally block molecular layer inhibition, as it was only under those artificial conditions that they (and we) found parallel fibers could drive Purkinje cell output in vivo.

\section{NEW ROLE(S) FOR MOLECULAR LAYER INHIBITION}

Beyond the more general conclusions just discussed, as is often the case with realistic models, the model makes a number of more detailed predications regarding the organization and function of cortical inhibitory mechanisms. In particular the model suggests different roles for the dendritic and somatic inhibition onto Purkinje cells provided by molecular layer interneurons. Traditionally, these two types of inhibition have been attributed to distinctly different cell types, the so-called "stellate cells" whose soma's are found high in the molecular layer and which provide inhibitory input directly to the Purkinje cell dendrite, and "basket cells" whose somas are found deep in the molecular layer and which provide a strong inhibitory input directly to the Purkinje cells soma (Palay and Chan, 1974; O'Donoghue et al., 1989; Castejon et al., 2001a; Donato et al., 2008; Wisden et al., 2009). However, our recent quantitative anatomical study of molecular layer interneurons suggests that these cells are, in fact, one homogenous population, whose probability of providing an inhibitory input directly to the soma simply goes up as the soma is deeper in the molecular layer (Sultan and Bower, 1998). Consistent with a single population of neurons, molecular layer interneurons with somas in the middle regions of the molecular layer provide both types of inputs. In this paper we will therefore distinguish between "stellate-like" dendritic and "basket-like" somatic inhibition rather than referring to stellate and basket-type cells.

While on the one hand our anatomical and modeling results suggests that molecular layer interneurons are one population of cells, our models predict that dendritic and somatic inhibition play different functional roles. While all molecular layer neurons receive input from the excitatory granule cell axons (Stell et al., 2007) it is known that these two types of inhibition have distinctly different postsynaptic effects on Purkinje cells. For example, dendritic (stellate-type) inputs have, at best, weak effects on the Purkinje cell soma (Vincent and Marty, 1996) while basket-type inputs are very effective in controlling Purkinje cell somatic spiking (Vincent and Marty, 1996). However, beyond these general descriptions, the functional or computational similarities and differences between these two types of molecular layer inhibition are not well understood (Kreiner and Jaeger, 2004; Barmack and Yakhnitsa, 2008b). 


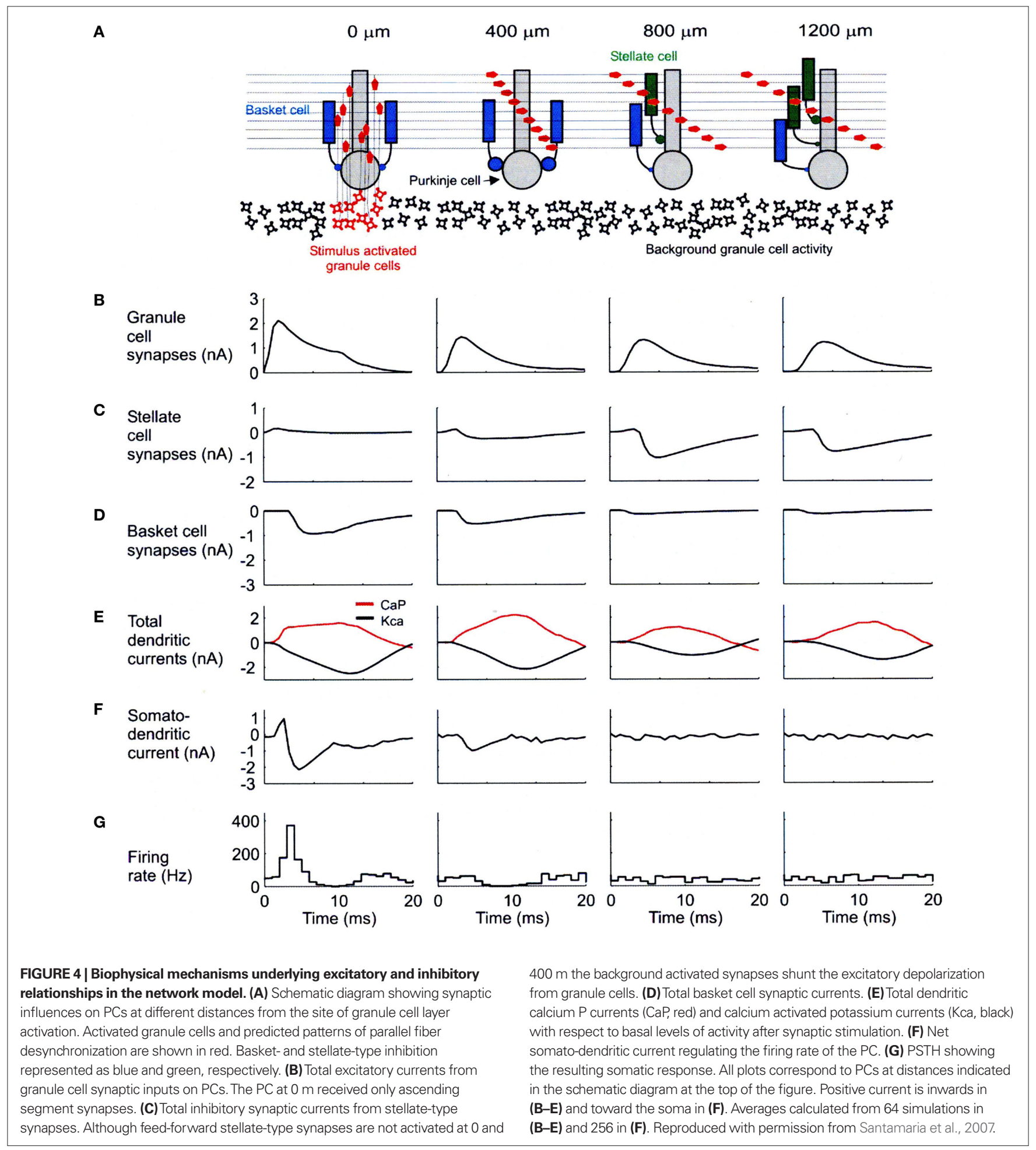

As shown in Figure 4, our network models have resulted in specific predictions regarding the effects and potential functional roles of dendritic and somatic molecular layer inhibition. The diagram at the top of this figure (Figure 4A) shows the simulated spatial/temporal pattern of granule cell synaptic input converging on modeled Purkinje cells located above (far left) and at the

indicated distances from a region of simulated granule cell layer excitation. The charts and graphs below each of these Purkinje cells (B-F) shown the relationships between several important modeling parameters reflecting the influence of molecular layer inhibition. The histograms at the bottom of this figure $(G)$ again show simulated responses for Purkinje cells at each distance. 
Space does not allow a complete description of the mechanisms underlying these relationships or, for example, the important analysis of parameter variations. For additional discussion as well as additional figures explaining model behavior, the reader is referred to Santamaria et al. (2007). Instead, the following discussion summarizes several predictions regarding the role of these two types of inhibition in cerebellar cortical networks. Each section will also consider independent supporting and contradictory evidence:

Feed-forward dendritic (stellate-type) inhibition specifically serves to counterbalance parallel fiber excitation in local regions of the Purkinje cell dendrite. The model specifically predicts that the lack of beam like activation of Purkinje cell along the parallel fibers is due to an effective balance established by the geometry of the network itself between dendritic (stellate-type) inhibition and parallel fiber excitation. This balance is manifest at the level of local dendritic segments, where feed-forward inhibition and parallel fiber excitation effectively produce a local clamp on the membrane voltage (Jaeger et al., 1997; Jaeger and Bower, 1999). This local voltage control, in turn, influences the activation balance between the much larger intrinsic voltage dependent calcium and potassium conductances in the Purkinje cell dendrite. Specifically, in the case of inhibition, allowing dendritic potassium currents to more effectively compensate for increasing voltage dependent calcium conductances. This in turn, results in no net flow of somatic/ dendritic current following an increase in parallel fiber activity, and therefore no effect of parallel fibers on the intrinsic spiking of the Purkinje cell (Figure 4F). Our models (Jaeger et al., 1997) as well as experimental results (Jaeger and Bower, 1999), suggest that this balance between parallel fiber excitation and molecular layer dendritic inhibition is key to the normal function of the Purkinje cell dendrite (Kreiner and Jaeger, 2004) and normal patterns of Purkinje cell somatic activity. In keeping with the general influence of dendritic inhibition on parallel fiber excitation predicted here, recent biophysical studies on the post synaptic responses of PC dendrites show that intra-dendritic excitatory responses are powerfully restricted in amplitude and duration by molecular layer inhibition (Brunel et al., 2004; Mittmann et al., 2005).

It may be important to point out explicitly that this influence of parallel fiber excitation and molecular layer inhibition on the dendrite of the Purkinje cell is very different in kind from the "integrate and fire" type functionality that dominates many existing models of Purkinje cell behavior (Medina and Mauk, 2000; Mauk and Ohyama, 2004; Carrillo et al., 2008). While the local dendritic influence of these two types of synapses could be considered to be a kind of local summing, our previous modeling results have shown that the "firing" of the Purkinje cell is under the secondary influence of the large voltage dependent conductances in the Purkinje cell dendrite and soma (Jaeger and Bower, 1999) and not the result of a simple sum of parallel fiber excitation and molecular layer inhibition. The interaction of the synaptic and intrinsic voltage dependent ionic conductances is far more complex than assumed in integrate and fire models. It is even likely that the local dendritic influences of parallel fiber excitation and molecular layer inhibition may be more complicated than simple summing, an issue we are currently addressing by constructed models based on serial EM reconstructions of local regions of the Purkinje cell dendrite (Lu et al., 2009).
Regardless of the local biophysical interaction of excitation and inhibition, in principle, the existence of an additional synapse in the feed-forward inhibitory pathway might at first seem to pose a problem for such a counterbalancing mechanism. However, a more detailed analysis of the network model indicates that the balancing effect emerges from the geometric and temporal structure of cerebellar cortical circuitry itself. First, the model suggests that the network derived desynchronization of parallel fiber volleys does, in fact, have an important consequence as it assures that Purkinje cells more distant from the site of granule cell layer activation do not receive an overwhelmingly large simultaneous excitatory synaptic parallel fiber excitatory input. Second, molecular layer interneurons are known to be electrically compact with very large input resistances (Hausser and Clark, 1997) assuring that they respond rapidly to granule cell synaptic input (Clark and Cull-Candy, 2002; Chavas and Marty, 2003; Suter and Jaeger, 2004; Crowley et al., 2007). It has even been suggested that activation by a single granule cell input is sufficient to produce a spike output from a molecular layer interneuron (Barbour, 1993). It is also now known that activation of molecular layer interneurons results in a rapid onset of inhibitory postsynaptic currents in Purkinje cells (Brunel et al., 2004; Steuber et al., 2007). There is even evidence for electrical synapses between molecular layer interneurons (Sotelo and Llinas, 1972; Mann-Metzer and Yarom, 2000) which could serve to speed or spread the establishment of dendritic inhibition. It should also be noted, however, that ascending segment synaptic activation occurs too rapidly and synchronously to be regulated by stellate type inhibition. Thus an equally important conclusion of this analysis is that ascending segment synapses influence Purkinje cells before dendritic inhibition can be established. In addition, ascending segment synaptic input projects onto a different part of the Purkinje cell dendrite than do the parallel fibers of the Purkinje cell dendrite (Gundappa-Sulur et al., 1999; Lu et al., 2009).

The effects of Feed-forward somatic (basket type) inhibition are profound and local. The previous sections described the model-derived prediction that the lack of Purkinje cell excitation at a distance following granule cell layer activation involves a dendritic level interaction between Stellate-type inhibition and parallel fiber activation resulting in no direct influence on Purkinje cell spiking output (Santamaria et al., 2007). In contrast, the model predicts that the influence of Basket-type somatic inhibition is restricted to Purkinje cells above and adjacent to the area of granule cell layer activation, and results in a direct effect on spiking output. As shown in Figure 4G and consistent with experimental data (Figures 1 and 3), Purkinje cells in these relative positions respond with a clear reduction in firing, which for Purkinje cells immediately overlying the activated granule cell region, usually follows the stimulus related increase in firing (Rokni et al., 2007). As illustrated by the currents shown in Figure 4D, the model predicts that, in both cases, this reduction in firing is due to the direct influence of a powerful and rapid basket-type inhibitory input on the soma and initial segment of the Purkinje cell.

There are several lines of experimental evidence that support model predictions regarding basket-type inhibition. First, it is well known that basket-type inhibition on Purkinje cells is rapid and profound (Vincent and Marty, 1996; Donato et al., 2008; Sakaba, 2008). Second, the prediction that basket-type influence is restricted to a region local to the site of granule cell layer activation 
is consistent with experimental data showing that molecular layer interneurons whose soma's are deep in the molecular layer have receptive fields similar to those of nearby and not distant regions of the granule cell layer (Ekerot and Jorntell, 2003; Jorntell and Ekerot, 2003; Barmack and Yakhnitsa, 2008b). While these restricted receptive fields have previously been attributed to a parallel fiber selection process (Ekerot and Jorntell, 2003; Jorntell and Ekerot, 2003; Dean et al., 2010), we believe that it is more likely that these interneurons may be specific targets for ascending granule cell axon bundles (Gundappa-Sulur et al., 1999; Lu et al., 2009). This suggestion is consistent with the observations that these cell's dendrites rise higher in the molecular layer than those of more superficial molecular layer interneurons making stellate-type connections (O'Donoghue et al., 1989; Sultan and Bower, 1998; Castejon et al., 2001a,b; Barmack and Yakhnitsa, 2008b) making them potential targets for ascending granule cell axons.

Recent optical imaging studies performed using an in vitro isolated cerebellar preparation have also shown the induction of likely inhibition overlying and immediately adjacent to a focal activation of the granule cell layer (Cohen and Yarom, 2000; Rokni et al., 2007). However, these authors attributed only the lateralized inhibitory optical signals (so called "off beam") to molecular layer inhibition, suggesting that the signals observed "on-beam" reflected the activity of Golgi cells within the granule cell layer (Cohen and Yarom, 2000). As already described, our models suggest that all nearby suppression of Purkinje cell firing is due to the large and power effects of basket-type inputs on the Purkinje cell soma, a result that would appear to be supported by more recent intracellular recordings by this group demonstrating that this "on-beam" optical signal is associated with actual membrane hyperpolarization in Purkinje cells (Rokni et al., 2007).

\section{FUNCTIONAL IMPLICATIONS}

Most modern models and theories of cerebellar cortex exclude molecular layer inhibition altogether (Ohyama et al., 2003; Yamazaki and Tanaka, 2007; Carrillo et al., 2008; Dean and Porrill, 2008; Traub et al., 2008; de Gruijl et al., 2009; Dean et al., 2010), and those in which it is included, have not distinguished between dendritic and somatic types of molecular layer inhibition (Chauvet and Chauvet, 1999; Medina et al., 2000; Silkis, 2000; De Jaeger and Proteau, 2003; Mauk and Ohyama, 2004; Steuber et al., 2007; Hong and Optican, 2008; Wulff et al., 2009). The model-based studies here suggest that although both forms of molecular layer inhibition are involved in controlling Purkinje cell responses to parallel fiber input, stellate (dendritic), and basket (somatic)-type inhibition are organized quite differently, with different spatial, temporal, and physiological effects and consequences.

\section{DENDRITIC INHIBITION AND PARALLEL FIBER EXCITATION CONTROL THE "STATE" OF THE PURKINJE CELL DENDRITE}

With the evidence continuing to accumulate that parallel fiber inputs do not activate Purkinje cells along a beam (see above), those who continue to believe that parallel fibers can and do directly drive Purkinje cell output have generally suggested that the lack of beams is due to a synaptic learning based selection process that leaves many if not most of the parallel fibers biophysically silent (Isope and Barbour, 2002; Jorntell and Ekerot, 2002; Ekerot and
Jorntell, 2003; Jorntell and Ekerot, 2003; Apps and Garwicz, 2005; Heck et al., 2007; Dean et al., 2010). Our results, however, suggest the alternate view that parallel fiber inputs are active, but under the control of feed-forward stellate-type molecular layer inhibition and are not intended to drive Purkinje cell output directly. This revised way of thinking about the influence of parallel fibers on Purkinje cells has important algorithmic implications for cerebellar cortical function (for further discussion: Bower, 2002). Instead of supporting a parallel fiber driven cerebellar learning function (Marr, 1969; Albus, 1971; Mauk and Ohyama, 2004; Ito, 2006; Thompson and Steinmetz, 2009), feed-forward dendritic stellate-type inhibition and parallel fiber excitation together are proposed to regulate the local dynamics of the Purkinje cell dendrite (Jaeger et al., 1997) with the large dendritic $\mathrm{Ca}$ and $\mathrm{K}$ dendritic currents providing most of the direct influence on Purkinje cell somatic spiking (Deschutter and Bower, 1994c; Sugimori et al., 1994; Jaeger et al., 1997; Womack and Khodakhah, 2003). In support of this idea, it has been pointed out by Mann-Metzer and Yarom (2002) and colleagues that the relatively "jittery" spiking response of molecular layer neurons to synaptic input with a duration that is independent of the strength of that input, is not consistent with a role in precise temporal coding. This behavior is consistent with a modulatory function however.

Algorithmically, our models and physiological data have suggested that this modulatory regulation of the dynamic balance between the large voltage dependent membrane condutances directly influences the response of the Purkinje cell to input from the ascending branch (Santamaria and Bower, 2005). Specifically, because the synapses of the ascending synapses contact only the smallest spiny branchlets of the Purkinje cell (Gundappa-Sulur et al., 1999; Lu et al., 2009), their voltage effects traverse regions of the dendrite under voltage clamp control of parallel fibers and feed-forward inhibition. We have interpreted this geometrical arrangement to suggest that the local parallel fiber/feed-forward voltage clamp mechanism serves functionally to modulate inputs from the ascending segment axons. Consistent with this prediction, we have shown using simultaneous granule cell layer and Purkinje cell recordings that any single activation of the granule cell layer does not necessarily result in a response from its overlying Purkinje cell (Lu et al., 2005).

\section{BASKET CELLS AND PARALLEL FIBERS}

One elegance of the arrangement between parallel fiber excitation and molecular layer dendritic (stellate) inhibition is that any activation of the granule cell layer produces both a strong influence on overlying Purkinje cells as well as a modulatory influence on more distant Purkinje cells [for more detail on this theory see Bower (2002)]. It is easy to see how such an algorithmic structure could extend seamlessly across the large extent of cerebellar cortex. However, what role does this leave for the basket-type somatic inhibition. Our modeling results predict that this type of inhibition is also specifically involved in controlling the influence of parallel fibers on Purkinje cell spiking output, however, not in as subtle or perhaps even as elegant a fashion as dendritic inhibition. Specifically, analysis of our network models predicts that basket-type input occurs at precisely the time that, otherwise, parallel fiber activity generated by local activation of the granule cell layer would otherwise directly influence the output of the Purkinje cell soma. In other words, the 
model suggests that the profound somatic inhibition generated by the basket-type input, in effect, assures that this locally generated parallel fiber input DOES NOT result in Purkinje cell output (Huang et al., 2006). In the absence of this inhibitory influence, Purkinje cells above and nearby activated regions of the granule cell layer produce uncharacteristically large and prolonged responses in the model (Santamaria et al., 2007) and in vivo (Mittmann et al., 2005; Rokni et al., 2007; Santamaria et al., 2007).

On the surface, this proposed inhibitory function of basket-type inputs might seem more akin to the traditional inhibitory role of sculpting or shaping excitatory responses (Bell and Grimm, 1969; Cohen and Yarom, 2000; Gao et al., 2006; Shin and De Schutter, 2006; Heck et al., 2007; Rokni et al., 2007; Barmack and Yakhnitsa, 2008b; Wisden et al., 2009). However, analysis of the model suggests instead, that basket-type inhibition is present to maintain the computational integrity of cortical processing. In other words, if the functional role of parallel fibers is to modulate the state of the dendrite and not provide a direct excitatory drive on Purkinje cell output, then some mechanism should exist to compensate for conditions in which parallel fibers might be able to directly drive somatic firing. While at a distance, the excitatory effect of parallel fibers can be counterbalanced by stellate-dendritic type inhibition, our models and physiological results suggest that this is not the case near the point of parallel fiber bifurcation. In these locations and with a sufficiently large activation of the granule cell layer, there is a risk that parallel fibers will directly drive Purkinje cell somatic output (Huang et al., 2006). Our models predicts that it is precisely in these regions that Basket-type inhibition can effectively shut down somatic Purkinje cell spiking. Further experimental evidence that this might be case is presented in Figure 5.

Originally intended to determine whether Purkinje cell beams might emerge with appropriately timed sequences of granule cell layer activations as subsequently suggested by (Heck, 1999), this figure shows Purkinje cell responses following stimulation of two different peripheral locations activating two different, but nearby, regions of the granule cell layer (from Bower and Woolston, 1983). Figure 5A shows the location of the two tactile stimuli used, in this case the ipsilateral and contralateral upper lip, while Figure 5B shows the corresponding two activated regions of the granule cell layer. Figure 5C shows responses recorded from a single Purkinje cell (location shown by the arrow in Figure 5B), resulting from stimulation of either peripheral locus alone (top and bottom), or stimulation of the two peripheral locations at different times (middle three histograms). It can be seen that this Purkinje cell which is located over the area of the granule cell layer activated by contralateral upper lip stimulation, as expected responds to stimulation of the contralateral upper lip with an increase in firing followed by a decrease in firing (top histogram). As also expected, this same Purkinje cell, which is adjacent to the region of the granule cell layer responding to ipsilateral stimulation, only responded with a decrease in spiking to ipsilateral stimulation (bottom histogram). When, however, the timing of both stimuli was adjusted so that the suppression of firing induced by ipsilateral stimulation temporally overlapped the increase in firing due to contralateral stimulation (middle histogram), the excitatory response even to the underlying granule cell layer input was suppressed. We suggest that the significance of this result is not that the excitatory response was being sculpted by surround inhibition, but that the basket-type somatic input was assuring that parallel fiber inputs did not influence the output of the cell. Based on the conduction velocity of parallel fibers, inhibition occurs at precisely the time that parallel fiber inputs resulting from activation of the contralateral stimulus would be converging on this Purkinje cell. Instead of summing with the ascending input to provide a more robust Purkinje cell output (Huang et al., 2006) as has been proposed for example by Huang et al. (2006), the response of the Purkinje cell is instead suppressed.

In summary, our studies suggest that basket-type molecular layer somatic inhibition may provide a mechanism to enforce what we are suggesting is a core computational feature of cerebellar cortical circuitry, that parallel fibers are modulatory and don't directly drive Purkinje cell somatic spiking. Obviously, this possibility further distances cerebellar function from the beam hypothesis and most current models and theories of cerebellar function (Dean et al., 2010), as it suggests that mechanisms specifically exist to assure that parallel fibers NEVER directly drive Purkinje cell output, regardless of the strength or pattern of granule cell layer activation, or any presumed plastic modification of synaptic strength driven by climbing fiber inputs (Dean et al., 2010). Previously, Braitenberg et al. (1997) have specifically suggested that Purkinje cell beams might emerge under special "tidal wave" conditions of granule cell layer activation. However, to date the only experimental support for this hypothesis has been generated in in vitro slice preparations under conditions in which cortical inhibition was blocked pharmacologically (Heck, 1995). As already discussed in and shown in Figure 5, our own efforts to look at "tidal wave effects" now almost 25 years ago, failed to find any such effects, in vivo specifically because of inhibitory mechanisms.

Of course, as always, it remains an open question how these experiments conducted in anesthetized preparations with one or at most two peripheral stimuli will illuminate cerebellar behavior in awake behaving preparations. Recordings in our laboratory from tactile regions of the cerebellum in awake behaving animals reveal that real behavior results in much more complex peripheral activation patterns producing much more complex patterns of granule cell layer activity (Hartmann and Bower, 1998, 2001). Future modeling efforts applying more realistic patterns of granule cell layer activity to the network model should, in principle, allow us to more rigorously test the basket-inhibition regulatory hypothesis under many different and more natural stimulus conditions.

\section{ALTERNATIVE VIEWS OF THE FUNCTION OF MOLECULAR LAYER INHIBITION}

As many neurobiologists are aware, cerebellar physiologists, anatomists, and theorists have been engaged in a long and complex debate regarding the role of synaptic plasticity in cerebellar cortical function (Ito, 2006). In part as a way to explain the contrast between the large number of parallel fibers as compared to a single climbing fibers converging on each Purkinje cell, Marr (1969) and Albus (1971) independently speculated that the climbing fiber determined (or instructed) which of the 10 s of thousands of parallel fibers influenced the output of a particular Purkinje cell. Underlying this assertion was the assumption that it was unlikely that Purkinje cell function could depend on a range of active parallel fibers from tens to hundreds of thousands synaptic inputs. One of the more inter- 


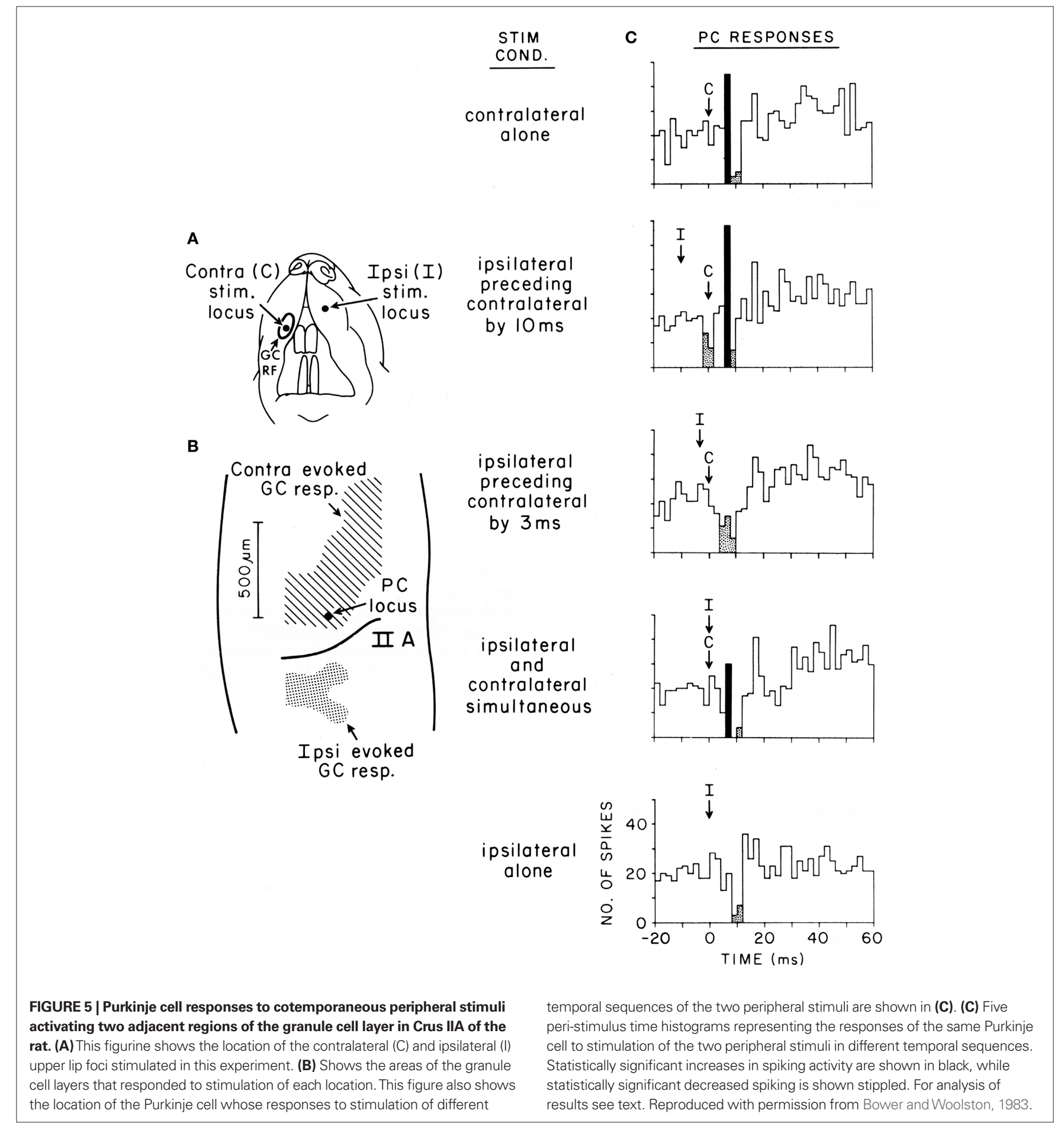

esting consequences of the modulatory relationship we propose between parallel fiber and stellate-type inputs, is that the feedforward nature of stellate-type inhibition, driven itself by parallel fibers, may very well result in a natural scaling between the amount of parallel fiber excitation and stellate-type inhibition. Thus, the local voltage clamp mechanism should be viable whether hundreds or tens of thousands of parallel fibers are active. This, of course, is a question for further realistic modeling.
The debate about cerebellum learning has also been strongly framed around the more specific question regarding the role of synaptic plasticity in cerebellar function. Physiological studies reporting plastic changes in parallel fiber synapses and more recently, plastic changes in synapses associated with molecular layer inhibition (Scelfo et al., 2008) have been central to the debate about cerebellar learning in general (Ito, 2006). Space does not allow a complete discussion of the many experiments supporting 
and questioning the role of synaptic plasticity in cortical function, however, there is one fundamental and important consequence of the view of the cerebellum emerging from our models that is relevant to this debate. Our results suggest that essential features of the connectivity and therefore the function of cortical networks in general and Purkinje cells and molecular layer interneurons in particular are determined in a fixed way by the spatial relationships between neuronal components. Thus, the receptive fields of Purkinje cells are determined by the receptive fields of granule cells in the underlying granule cell layer (Bower and Woolston, 1983) via synapses on the ascending segment of the granule cell axon, and not by a synaptic plasticity rule or the climbing fiber system (Dean et al., 2010). Similarly, our models predict that the receptive fields of molecular layer interneurons are determined by their spatial location relative to activity in the granule cell layer, not by some plasticity synaptic mechanism (Dean et al., 2010). This is not to say that synapses are not plastic, all synapses are plastic, it is to suggest that the fundamental relationships between neurons in the cerebellum are determined spatially and are not "learned."

Experimental evidence purporting to show that receptive fields of both Purkinje cells and now molecular layer interneurons are "learned" have not directly compared the responses of either type of neuron directly to the receptive field properties of the underlying granule cell layer in the same animals (Dean et al., 2010). While there are regularities in the afferent input maps to the granule cell layer in the cerebellum (Bower and Kassel, 1990), these patterns are not regular enough to allow receptive field relationships to be understood by aggregating data across multiple animals (Jorntell and Ekerot, 2003). While we have previously shown by direct comparison in the same animals, that Purkinje cell receptive fields are determined by the receptive fields of the underlying granule cell layer (Bower and Woolston, 1983), based on the studies presented here, we would predict that molecular layer interneurons whose soma's are deep in the molecular layer (and therefore making basket-type connections) would have receptive fields similar to those of the underlying granule cell layer. On the other hand, more superficial molecular layer interneurons should have broader receptive fields reflecting the multiple afferent inputs typically seen in larger regions of the granule cell layer (Bower and Kassel, 1990). In fact, those receptive fields should specifically reflect the origins of the parallel fibers running in their region of the cerebellum. Intermediate depth molecular layer interneurons should be intermediate. As a corollary, we also predict that molecular layer interneurons in the deeper layers of the molecular layer would receive their predominant granule cell synaptic input from ascending granule cell axons, while more superficial molecular layer interneurons would receive a larger proportion of their inputs from parallel fibers. This prediction is consistent with the ratio of these two different types of synapses in the deep and superficial regions of the granule cell layer (Gundappa-Sulur et al., 1999) as well as with the vertically elongated shape of the dendrites of deep molecular layer interneurons (O’Donoghue et al., 1989; Sultan and Bower, 1998; Castejon et al., 2001a,b; Barmack and Yakhnitsa, 2008b). Both these anatomical and physiological experiments are doable, but have not yet been done.

The results presented here may also have important implications for the more general issue of information coding in Purkinje cell spike trains. Recently, it has been suggested that decreases in Purkinje cell spiking, at least in part associated with cortical inhibitory mechanisms, either reflect changes in coding state (Rokni et al., 2009) or may even themselves be part of the Purkinje cell neural code (De Schutter and Steuber, 2009). With respect to coding state, there is some evidence, mostly in vitro (Rokni et al., 2009), but also in awake preparations (Yartsev et al., 2009), that Purkinje cells may be "bistable" exhibiting "upstates" and "downstates." These states are proposed to change the way in which Purkinje cells respond to synaptic input including inhibition (Rokni et al., 2009). But it has also been suggested that synaptic inputs from parallel fibers and molecular layer inhibitory neurons might be involved in switching between these states (Rokni et al., 2009). We have previously shown that the general level of background synaptic activity provided by parallel fibers and stellate-type inputs can have a profound effect on the firing behavior of Purkinje cells (Jaeger et al., 1997) and a principle conclusion of our work to date is that the primary role of parallel fiber excitation and molecular layer inhibition is to modulate the dynamical state of the Purkinje cell dendrite (Bower, 2002). In principle, the role for dendritic inhibition proposed here is consistent with a role in such "state changes" although we also suspect that the climbing fiber input is involves as well.

In addition to these longer time scale "state" modulations of Purkinje cell spiking, it has also recently been suggested that intermediate duration pauses in spiking, on the order of 10's to 100's of milliseconds might be a mechanism for coding specific forms of information for transfer to the deep cerebellar nuclei (De Schutter and Steuber, 2009) (Kreiner and Jaeger, 2004; Jaeger, 2007). It has further been suggested that a principle role for cerebellar LTP is in regulating the duration of these pauses in spiking (De Schutter and Steuber, 2009). In the cerebellum, this argument is related to a long tradition of speculations regarding Purkinje cell output (Eccles et al., 1967), that effective excitation in the deep cerebellar nuclei can be achieved by inhibiting the inhibitory output of Purkinje cells (Jaeger, 2007; De Schutter and Steuber, 2009).

While these are interesting ideas, and some are based on models efforts (De Schutter and Steuber, 2009), the question with respect to the current paper is what role molecular layer inhibition might play in the short term pausing mechanism (Jaeger, 2007). As is generally the case with Purkinje cells, the answer to this question is made more complicated by the large intrinsic voltage dependent conductances found in the Purkinje cell dendrites and soma. Evidence suggests that the interplay of these conductances all by themselves can result in pauses in spiking activity in the absence of inhibitory synaptic influence (Steuber et al., 2007; De Schutter and Steuber, 2009). With respect to inhibition, it has recently been proposed that the role of cortical inhibitory circuits is more in coordinating, or synchronizing pauses between nearby Purkinje cells than in generating the pauses per se (De Schutter and Steuber, 2009). Our predictions that basket-type inhibition is mostly a local effect, close to a region of granule cell activation is compatible with such a coordinating mechanism. Unfortunately, however, as is typical for theories of the role of molecular layer inhibition in general, current speculations don't distinguish between stellate and basket forms of inhibition (De Schutter and Steuber, 2009). In previous modeling studies, we have shown that while rapid increases in overall stellate-type dendritic inhibitory input can influence the timing of individual Purkinje cell spikes generated in the soma (Jaeger et al., 1997), these influences occur over millisecond times scales not the 10s or 100s of milliseconds assumed associated with information coding (Steuber et al., 2007; 
De Schutter and Steuber, 2009). Further, in the absence of perhaps artificially rapid increases in dendritic inhibition, we would predict that this type of inhibition only influences cell spiking very indirectly through subtle changes in local dendritic voltage. Thus, it seems unlikely that stellate-type inhibition would have much of a direct effect on spike coding reflected in pauses in spiking.

\section{EVOLUTIONARY CONSIDERATION}

Finally, there is another likely important consideration with respect to a direct role of especially basket-type molecular layer inhibition in neural coding mechanisms, and that is that this type of synaptic connection is only found in mammals and birds (Llinas and Hillman, 1969; Larsell, 1972; Larsell and Jansen, 1972). Anatomical studies have shown that the cerebellar cortex of most fish (Waks and Westerman, 1970), amphibians (Midtgaard, 1992) and some reptiles (Llinas et al., 1969) lack basket-type connections altogether. In those fish, amphibians, and reptiles whose Purkinje cell soma's do receive inhibitory projections from molecular layer interneurons they are of the more traditional "en passant" rather than the specialized basket-type (Llinas et al., 1969; Waks and Westerman, 1970; Midtgaard, 1992).

The fact that only mammals and birds have been shown to have true Basket-type connections would seem to produce additional difficulties for an information coding mechanism based on pauses due to this type of inhibitory input. Presumably, principles of Purkinje cell coding and cerebellar function are not significantly different in non-mammalian and non-avian species. Instead, we would suggest that the limited comparative distribution of baskettype connections is more consistent with the idea that these inputs restrict parallel fiber synaptic influences on Purkinje cell outputs, making sure that Purkinje cells don't spike to this type of input.

Reexamining our network modeling results from more of an evolutionary perspective, there are two features of mammalian cerebellar cortex that make basket-cell type inputs necessary: very large numbers of parallel fiber inputs per Purkinje cell, and Purkinje cell dendrites that are electronically compact. It follows that we would predict that species lacking basket-type inhibitory connections should either have significantly fewer parallel fibers per Purkinje cell and/or have significantly less electrotonically compact dendrites. To test these predictions, we are currently engaged in a comparative study of multiple vertebrate species to determine both the ratio of granule cells to Purkinje cells and the passive electrical properties of those Purkinje cells. Preliminary results suggest that, in fact, mammals and birds generally have the highest ratio of granule cells per Purkinje cells and also have the most electrotonically compact Purkinje cells (Cornelis et al., 2007; Wilcox et al., 2009). The mormyrid fish may be an exception, but interestingly enough, there is some evidence that they may also have a more basket-like inhibitory connection (Grant et al., 1998).

While these experiments are still underway, the results to date are consistent with the suggestion that Basket-type inhibition is an evolutionary adaptation to changes in cortical properties

\section{REFERENCES}

Albus, J. S. (1971). A theory of cerebellar function. Math. Biosci. 10, 25-61.

Andersen, P. (2006). Inhibitory circuits in the thalamus and hippocampus - an appraisal after 40 years. Prog. Neurobiol. $78,264-271$.
Apps, R., and Garwicz, M. (2005). Anatomical and physiological foundations of cerebellar information processing. Nat. Rev. Neurosci. 6, 297-311.

Barbour, B. (1993). Synaptic currents evoked in Purkinje cells by stimulating

influencing the convergence of parallel fiber inputs on Purkinje cells. The idea that a significant structural component of the mammalian cerebellar cortical network may be an adaptation to control an unwanted consequence of the evolutionary development of the cerebellum is novel. However, these types of adaptations are increasingly being reported in the study of gene regulatory networks, for example, where one can argue that both the function and structure of a complex biological regulatory mechanism are more accessible (Bolouri, 2008).

\section{THE ROLE OF MODELING IN UNDERSTANDING BRAIN BIOPHYSICS AND FUNCTION}

Finally, as the interest in molecular layer inhibition has continued to rise, so do speculations regarding both the physiology and function of this important component of cerebellar cortex. As part of this new trend, a recent paper recording cerebellar neuronal responses to vestibular stimulation in the mouse, Barmack and Yakhnitsa (2008a) interpreted physiological recordings obtained from randomly sampled mossy fiber afferents, granule cells, Purkinje cells and climbing fibers to suggest that it is climbing fibers and not granule cells that provide the primary drive on molecular layer interneurons. Without distinguishing the morphological and physiological differences between stellate and basket-type inhibition, and without carefully quantifying the spatial relationships between the recorded neurons, perhaps the most remarkable aspect of this speculation is that the authors themselves acknowledge that there is no anatomical evidence for direct climbing fiber input to molecular layer interneurons. In effect, the authors simply assumed that correlation is strong evidence for causation, even in the absence of a possible anatomical mechanism. Perhaps the principle take home message from the current paper, and our modeling studies to date, is that teasing out the actual causal relationships between neurons in even a structure as generally uniform as the cerebellar cortex requires tools that allow complex forms of causality to be discovered, explored, and tested. While our new interpretation for the role of molecular layer inhibition in the cerebellum will likely be controversial, it is slowly becoming apparent in numerous other brain regions, in part due to modeling, that traditional relatively simple interpretations of the interaction of synaptic excitation and inhibition in brain circuitry may not apply (Chance et al., 2002; Kreiner and Jaeger, 2004; Scelfo et al., 2008). Further, the causal speculations made here are quantified in the form of a biophysically realistic model, available to anyone to download and critique. It is our view that real progress in understanding structure/function relationships in neuronal circuits will increasingly depend on the use and sharing of such biophysically based models.

\section{ACKNOWLEDGMENTS}

This work was supported by a grant from the National Science Foundation.

individual granule cells. Neuron 11 759-769.

Barmack, N. H., and Yakhnitsa, V. (2008a) Distribution of granule cells projecting to focal Purkinje cells in mouse uvula-nodulus. Neuroscience 156 216-221.
Barmack, N. H., and Yakhnitsa, V. (2008b). Functions of Interneurons in Mouse cerebellum. J. Neurosci. 28, 1140-1152.

Bell, C., and Grimm, R. (1969). Discharge properties of Purkinje cells recorded on single and double 
microelectrodes. J. Neurophysiol. 32, 1044-1055.

Bolouri, H. (2008). Computational Modeling of Gene Regulatory Networks - A Primer. London: Imperial College Press.

Bower, J. M. (1990). "Reverse engineering the nervous system: an anatomical, physiological, and computer based approach," in An Introduction to Neural and Electronic Networks, eds S. Zornetzer, J. Davis and C. Lau (New York: Academic Press), pp. 3-24.

Bower, J. M. (2002). The organization of cerebellar cortical circuitry revisited: implications for function. Ann. N. Y. Acad. Sci. 978, 135-155.

Bower, J. M., and Kassel, J. (1990). Variability in tactile projection patterns to cerebellar folia crus IIA of the Norway rat. J. Comp. Neurol. 302, 768-778.

Bower, J. M., and Woolston, D. C. (1983). Congruence of spatial organization of tactile projections to granule cell and Purkinje cell layers of cerebellar hemispheres of the albino rat: vertical organization of cerebellar cortex. J. Neurophysiol. 49, 745-766.

Braitenberg, V., and Atwood, R. P. (1958). Morphological observations in the cerebellar cortex. J. Comp. Neurol. 109, 1-34.

Braitenberg, V., Heck, D., and Sultan, F. (1997). The detection and generation of sequences as a key to cerebellar function: experiments and theory. Behav. Brain Sci. 20, 229-277.

Brown, M. E., and Ariel, M. (2009). Topography and response timing of intact cerebellum stained with absorbance voltage-sensitive dye. J. Neurophysiol. 101, 474-490.

Brunel, N., Hakim, V., Isope, P., Nadal, J. P., and Barbour, B. (2004). Optimal information storage and the distribution of synaptic weights: perceptron versus Purkinje cell. Neuron 43, 745-757.

Carrillo, R. R., Ros, E., Boucheny, C., and Coenen, O. J. (2008). A realtime spiking cerebellum model for learning robot control. BioSystems 94, 18-27.

Castejon, O., Castejon, H., and sims, P. (2001a). Light microscopy, confocal laser scanning microscopy, scanning and transmission electron microscopy of cerebellar basket cells. J. Submicrosc. Cytol. Pathol. 33, 23-32.

Castejon, O. J., Castejon, H. V., and Sims, P. (2001b). Light microscopy, confocal laser scanning microscopy, scanning and transmission electron microscopy of cerebellar basket cells. J. Submicrosc. Cytol. Pathol. 33, 23-32.

Chance, F. S., Abbott, L. F., and Reyes, A. D. (2002). Gain modulation from background synaptic input. Neuron $35,773-782$.
Chauvet, P., and Chauvet, G. A. (1999). Purkinje local circuits with delays: mathematical conditions of stability for learning and retrieval. Neural Netw. $12,59-77$.

Chavas, J., and Marty, A. (2003). Coexistence of excitatory and inhibitory GABA synapses in the cerebellar interneuron network. J. Neurosci. 23, 2019-2031.

Clark, B. A., and Cull-Candy, S. G. (2002). Activity-dependent recruitment of extrasynaptic NMDA receptor activation at an AMPA receptor-only synapse. J. Neurosci. 22, 4428-4436.

Cohen, D., and Yarom, Y. (1998). Patches of synchronized activity in the cerebellar cortex evoked by mossy-fiber stimulation: questioning the role of parallel fibers. Proc. Natl. Acad. Sci. U.S.A. 95, 15032-15036.

Cohen, D., and Yarom, Y. (2000). Cerebellar on-beam and lateral inhibition: two functionally distinct circuits. J. Neurophysiol. 83, 1932-1940.

Cornelis, H., Lu, H., Georgi, J. S., and Bower, J. M. (2007). Comparative computational study of cerebellar Purkinje cell form and function. Abstr. Soc. Neurosci. 33 409.21.

Crowley, J. J., Carter, A. G., and Regehr, W. G. (2007). Fast vesicle replenishment and rapid recovery from desensitization at a single synaptic release site. $J$. Neurosci. 27, 5448-5460.

de Gruijl, J. R., van der Smagt, P., and De Zeeuw, C. I. (2009). Anticipatory grip force control using a cerebellar model. Neuroscience 162, 777-786.

De Jaeger, D., and Proteau, L. (2003). The relative efficacy of different forms of knowledge of results for the learning of a new relative timing pattern. Q. J. Exp. Psychol. A. 56, 621-640.

De Schutter, E., and Steuber, V. (2009). Patterns and pauses in Purkinje cell simple spike trains: experiments modeling and theory. Neuroscience $162,816-826$.

de Solages, C., Szapiro, G., Brunel, N., Hakim, V., and Isope, P. (2008). Highfrequency organization and synchrony of activity in the purkinje cell layer of the cerebellum. Neuron 58, 775-788.

Dean, P., and Porrill, J. (2008). Adaptivefilter models of the cerebellum: computational analysis. Cerebellum 7 , 567-571.

Dean, P., Porrill, J., Ekerot, C.-F., and Jorntell, H. (2010). The cerebellar microcircuit as an adaptive filter: experimental and computational evidence. Nat. Rev. Neurosci. 11, 30-40.

Deschutter, E., and Bower, J. (1994a). An active membrane model of the cerebellar Purkinje-cell.1. Simulation of current clamps in slice. J. Neurophysiol. $71,375-400$.
Deschutter, E., and Bower, J. (1994b). An active membrane model of the cerebellar purkinje-cell.2. Simulation of synaptic responses. J. Neurophysiol. 71, 401-419.

Deschutter, E., and Bower, J. (1994c). Simulated responses of cerebellar purkinje-cells are independent of the dendritic location of granule cell synaptic inputs. Proc. Natl. Acad. Sci. USA 91, 4736-4740.

Donato, R., Rodrigues, R. J., Takahashi, M., Tsai, M. C., and Soto, D. (2008). GABA release by basket cells onto Purkinje cells, in rat cerebellar slices, is directly controlled by presynaptic purinergic receptors, modulating $\mathrm{Ca} 2+$ influx. Cell Calcium 44, 521-532.

Eccles, J. C., Ito, M., and Szentagothai, J. (1967). The Cerebellum as a Neuronal Machine. Berlin: Springer.

Eccles, J. C., Llinas, R., and Sasaki, K. (1966). Parallel fibre stimulation and the responses induced thereby in the Purkinje cells of the cerebellum. Exp. Brain Res. 1, 17-29.

Eccles, J. C., Sabah, N. H., Scmidt, R. F., and Taborikova, H. (1972). Cutaneous mechanoreceptors influencing impulse discharges in cerebellar cortex. I. In mossy fibers. Exp. Brain Res. $15,245-260$.

Ekerot, C. F., and Jorntell, H. (2003). Parallel fiber receptive fields: a key to understanding cerebellar operation and learning. Cerebellum 2, 101-109.

Gao, W., Chen, G., Reinert, C., and Ebner, T. J. (2006). Cerebellar cortical molecular layer inhibition is organized in parasagittal zones. J. Neurosci. 26 , 8377-8387.

Garwicz, M., and Andersson, G. (1992) Spread of synaptic activity along parallel fibers in cat cerebellar anterior lobe. Exp. Brain Res. 88, 615-622.

Grant, K., Sugawara, Y., Gomez, L., Han, V. Z., and Bell, C. C. (1998). The mormyrid electrosensory lobe in vitro: physiology and pharmacology of cells and circuits. J. Neurosci. 18 6009-6025.

Gundappa-Sulur, G., De Schutter, E., and Bower, J. M. (1999). The ascending branch of the granule cell axon: a significant component in cerebellar cortical circuitry. J. Comp. Neurosci. 406, 580-596.

Hartmann, M., and Bower, J. M. (1998). Oscillatory activity (spindling) in the cerebellum of unrestrained rats. $J$. Neurophysiol. 80, 1598-1604.

Hartmann, M., and Bower, J. M. (2001). Tactile responses in the granule cell layer of cerebellar folium Crus Iia of freely behaving rats. J. Neurosci. 28 , 3549-3563.

Harvey, R. J., and Napper, R. M. A. (1991). Quantitative studies of the mammalian cerebellum. Prog. Neurobiol. 36, 437-463.

Hausser, M., and Clark, B. A. (1997). Tonic synaptic inhibition modulates neuronal output pattern and spatiotemporal synaptic integration. Neuron 19, 665-678.

Heck, D. (1995). Sequential stimulation of guinea-pig cerebellar cortex in-vitro strongly affects Purkinje-cells via parallel fibers. Naturwissenschaften 82, 201-203.

Heck, D. (1999). Sequential stimulation of rat and guinea pig cerebellar granular cells in vitro leads to increasing population activity in parallel fibers. Neurosci. Lett. 263, 137-140.

Heck, D. H., Thach, W. T., and Keating, J. G. (2007). On-beam synchrony in the cerebellum as the mechanism for the timing and coordination of movement. Proc. Natl. Acad. Sci. U.S.A. 104, 7658-7663.

Holtzman, T., Rajapaksa, T., Mostofi, A., and Edgley, S. A. (2006). Different responses of rat cerebellar Purkinje cells and Golgi cells evoked by widespread convergent sensory inputs. $J$. Physiol. (Lond) 574, 491-507.

Hong, S., and Optican, L. M. (2008). Interaction between Purkinje cells and inhibitory interneurons may create adjustable output waveforms to generate timed cerebellar output. PLoS ONE 3, e(2770). doi:10.1371/journal. pone. 0002770

Houk, J. C., and Walsh, J. V. (1971). The length and organization of parallel fibers. Proc. Int. Congr. Phy. Sci. 9, 776.

Huang, C., Wang, L., and Huang, R. H. (2006). Cerebellar granule cell: ascending axon and parallel fiber. Eur. J. Neurosci. 23, 1731-1737.

Isope, P., and Barbour, B. (2002). Properties of unitary granule cell - Purkinje cell synapses in adult rat cerebellar slices. J. Neurosci. 22, 9668-9678.

Ito, M. (2006). Cerebellar circuitry as a neuronal machine. Prog. Neurobiol. 78, 272-303.

Jaeger, D. (2007). Pauses as neural code in the cerebellum. Neuron 54, 9-10.

Jaeger, D., and Bower, J. M. (1994). Prolonged responses in rat cerebellar Purkinje cells following activation of the granule cell layer: an intracellular in vitro and in vivo investigation. Exp. Brain Res. 100, 200-214.

Jaeger, D., and Bower, J. M. (1999). Synaptic control of spiking in cerebellar Purkinje cells: dynamic current clamp based on model conductances. J. Neurosci. 19, 6090-6101.

Jaeger, D., De Schutter, E., and Bower, J. M. (1997). The role of synaptic and voltage-gated currents in the control of Purkinje cell spiking: a modeling study. J. Neurosci. 17, 91-106. 
Jorntell, H., and Ekerot, C. F. (2002). Reciprocal bidirectional plasticity of parallel fiber receptive fields in cerebellar Purkinje cells and their afferent interneurons. Neuron 34, 797-806.

Jorntell, H., and Ekerot, C. F. (2003). Receptive field plasticity profoundly alters the cutaneous parallel fiber synaptic input to cerebellar interneurons in vivo. J. Neurosci. 23, 9620-9631.

Jorntell, H., and Ekerot, C.-F. (2006). Properties of somatosensory synaptic integration in cerebellar granule cells in vivo. J. Neurosci. 26, 11786-11797.

Kolb, F. P., Arnold, G., Lerch, R., Straka, H., and Buttner-Ennerver, J. (1997). Spatial distribution of field potential profiles in the cat cerebellar cortex evoked by peripheral and central inputs. Neuroscience 81, 1155-1181.

Kreiner, L., and Jaeger, D. (2004). Synaptic shunting by a baseline of synaptic conductances modulates responses to inhibitory input volleys in cerebellar Purkinje cells. Cerebellum 3, 112-125.

Larsell, O. (1972). The Comparitive Anatomy and Histology of the Cerebellum from Monotremes through Apes. Minneapolis: University of Minnesotta Press.

Larsell, O., and Jansen, J. (1972). The Comparitive Anatomy and Histology of the Cerebellum: the Human Cerebellum, Cerebellar Connections, and Cerebellar Cortex. Minneapolis: University of Minnesotta Press.

Llinas, R. (1982). "General discussion: radial connectivity in the cerebellar cortex: a novel view regarding the functional organization of the molecular layer," in The Cerebellum: New Vistas (Exp. Brain Res. Suppl. Vol. 6), eds S. L. Palay and V. Chan-Palay (New York: Springer Verlag), pp. 189-194.

Llinas, R., Bloedel, J. R., and Hillman, D. E. (1969). Functional characterization of neuronal circuitry of frog cerebellar cortex. J. Neurophysiol. 32, 847-870.

Llinas, R., and Hillman, D. E. (1969). "Physiological and morphological organization of cerebellar circuits in various vertebrates," in Neurobiology of Cerebellar Evolution and Development, ed. R Llinas (Chicago: American Medical Association), pp. 43-76.

Llinas, R., and Sugimori, M. (1980). Electrophysiological properties of in vitro Purkinje cell dendrites in mammalian cerebellar slices. J. Physiol. 305, 197-213.

Lu, H., Esquivel, A. V., and Bower, J. M. (2009). 3D electron microscopic reconstruction of segments of rat cerebellar purkinje cell dendrites receiving ascending and parallel fiber granule cell synaptic inputs. J. Comp. Neurol. 514, 583-594.
Lu, H., Hartmann, M. J., and Bower, J. M. (2005). Correlations between purkinje cell single-unit activity and simultaneously recorded field potentials in the immediately underlying granule cell layer. J. Neurophysiol. 94, 1849-1860.

Mann-Metzer, P., and Yarom, Y. (2000). Electrotonic Coupling Synchronizes Interneuron Activity in the Cerebellar Cortex. Prog. Brain Res. $124,115-122$.

Mann-Metzer, P., and Yarom, Y. (2002). Jittery trains induced by synapticlike current in cerebellar inhibitory interneurons. J. Neurophysiol. 87, 149-186.

Marr, D. (1969). A theory of cerebellar cortex. J. Physiol. (Lond.) 202, 437-471.

Mauk, M. D., and Ohyama, T. (2004). Extinction as new learning versus unlearning: considerations from a computer simulation of the cerebellum. Learn. Mem. 11, 566-571.

McKay, B.E., Engbers, J.D. T., Mehaffey, W. H., Gordon, G. R. J., and Molineux, M. L., (2007). Climbing fiber discharge regulates cerebellar functions by controlling the intrinsic characteristics of Purkinje cell output. J. Neurophysiol. 97, 2590-2604.

Medina, J. F., Garcia, K. S., Nores, W. L., Taylor, N. M., and Mauk, M. D. (2000). Timing mechanisms in the cerebellum: testing predictions of a large-scale computer simulation. J. Neurosci. 20, 5516-5525.

Medina, J. F., and Mauk, M. D. (2000). Computer simulation of cerebellar information processing. Nat. Neurosci. 3(Suppl.), 1205-1211.

Midtgaard, J. (1992). Stellate cell inhibition of Purkinje cells in the turtle cerebellum in vitro. J. Physiol. (Lond.) 457, 355-367.

Mittmann, W., Koch, U., and Hausser, M. (2005). Feed-forward inhibition shapes the spike output of cerebellar Purkinje cells. J. Physiol. (Lond.) 563, 369-378.

Mugnaini, E. (1972). "The histology and cytology of the cerebellar cortex." in The Comparitive Anatomy and Histology of the Cerebellum: The Human Cerebellum, Cerebellar Connections, and Cerebellar Cortex., eds O. Larsell and J. Jansen (Minneapolis: University of Minnesota Press), pp. 201-262.

O'Donoghue, D. L., King, J. S., and Bishop, G. A. (1989). Physiological and anatomical studies of the interactions between Purkinje cells and basket cells in the cat's cerebellar cortex: evidence for a unitary relationship. J. Neurosci. 9, 2141-2150.

Ohyama, T., Nores, W. L., Murphy, M., and Mauk, M. D. (2003). What the cerebellum computes. Trends Neurosci. 26, 222-227.

Palay, S. L., and Chan, P. V. (1974). Cerebellar Cortex: Cytology and Organization. Berlin: Springer.

Pichitpornchai, C., Rawson, J. A., and Rees, S. (1994). Morphology of parallel fibres in the cerebellar cortex of the rat: an experimental light and electron microscopic study with biocytin. J. Comp. Neurol. 342, 206-220.

Rokni, D., Llinas, R., and Yarom, Y. (2007). Stars and stripes in the cerebellar cortex: a voltage sensitive dye study. Front. Syst. Neurosci. 1, 1 .

Rokni, D., Llinas, R., and Yarom, Y. (2008). The morpho/functional discrepancy in the cerebellar cortex: looks alone are deceptive. Front. Neurosci. 2, 192-198.

Rokni, D., Tal, Z., Byk, H., and Yarom, Y. (2009). Regularity, variability and bi-stability in the activity of cerebellar Purkinje cells. Front. Cell. Neurosci. 3, 1-9.

Ruigrok, T. J. (2010). Ins and outs of cerebellar modules. Cerebellum. doi 10.1007/s12311-010-0164-y

Sakaba, T. (2008). Two Ca(2+)-dependent steps controlling synaptic vesicle fusion and replenishment at the cerebellar basket cell terminal. Neuron 57, 406-419.

Santamaria, F., and Bower, J. M. (2005). Background synaptic activity modulates the response of a modeled purkinje cell to paired afferent input. J. Neurophysiol. 93, 237-250.

Santamaria, F., Tripp, P. G., and Bower, J. M. (2007). Feedforward inhibition controls the spread of granule cellinduced Purkinje cell activity in the cerebellar cortex. J. Neurophysiol. 97 , 248-263.

Scelfo, B., Sacchetti, B., and Strata, P. (2008). Learning-related long-term potentiation of inhibitory synapses in the cerebellar cortex. Proc. Natl. Acad. Sci. U.S.A. 105, 769-774

Shin, S. L., and De Schutter, E. (2006). Dynamic synchronization of Purkinje cell simple spikes. J. Neurophysiol. 96, 3485-3491.

Silkis, I. (2000). Interrelated modification of excitatory and inhibitory synapses in three-layer olivary-cerebellar neural network. BioSystems 54, 141-149.

Sims, R. E., and Hartell, N. A. (2005). Differences in transmission properties and susceptibility to long-term depression reveal functional specialization of ascending axon and parallel fiber synapses to Purkinje cells. J. Neurosci. 25, 3246-3257.

Sims, R. E., and Hartell, N. A. (2006). Differential susceptibility to synaptic plasticity reveals a functional specialization of ascending axon and parallel fiber synapses to cerebellar Purkinje cells. J. Neurosci. 26, 5153-5159.

Sotelo, C., and Llinas, R. (1972). Specialized membrane junctions between neurons in the vertebrate cerebellar cortex. $J$. Cell Biol. 53, 271-289.

Stell, B. M., Rastaing, P., Triller, A., and Marty, A. (2007). Activation of presynaptic GABAA receptors induces glutamate release from parallel fiber synapses. J. Neurosci. 27, 9022-9031.

Steuber, V., Mittmann, W., Hoebeek, F. E., Silver, R. A., and De Zeeuw, C. I. (2007). Cerebellar LTD and pattern recognition by Purkinje cells. Neuron 54, 121-136.

Sugimori, M., Kay, A. R., and Llinas, R. (1994). The persistent $\mathrm{Na}+$ current in cerebellar Purkinje cells has a single channel conductance distinct from the inactivating current. Abstr. Soc. Neurosci. 20(Pt 1), 63.

Sultan, F., and Bower, J. M. (1998). Quantitative Golgi study of the rat cerebellar molecular layer interneurons using principal component analysis. J. Comp. Neurol. 393, 353-373.

Suter, K. J., and Jaeger, D. (2004). Reliable control of spike rate and spike timing by rapid input transients in cerebellar stellate cells. Neuroscience 124, 305-317.

Thompson, R. F., and Steinmetz, J. E. (2009). The role of the cerebellum in classical conditioning of discrete behavioral responses. Neuroscience 162, 732-755

Tolbert, D. L., Conoyer, B., and Ariel, M. (2004). Quantitative analysis of granule cell axons and climbing fiber afferents in the turtle cerebellar cortex. Anat. Embryol. (Berl). 209, 49-58.

Traub, R. D., Middleton, S. J., Knopfel, T., and Whittington, M.A. (2008). Model of very fast $(>75 \mathrm{~Hz})$ network oscillations generated by electrical coupling between the proximal axons of cerebellar Purkinje cells. Eur. J. Neurosci. 28, 1603-1616.

Vincent, P., and Marty, A. (1996). Fluctuations of inhibitory postsynaptic currents in Purkinje cells from rat cerebellar slices. J. Physiol. 494 (Pt 1), 183-199.

Vranesic, I., Iijima, T., Ichikawa, M., Matsumoto, G., and Knopfel, T. (1994). Signal transmission in the parallel fiber Purkinje-cell system visualized by high-resolution imaging. Proc. Natl. Acad. Sci. U.S.A. 91, 13014-13017.

Waks,M.D., and Westerman, R.A. (1970). Inhibition of Purkinje cells in the cerebellum of the teleost Salmo gairdneri Richardson. Comp. Biochem. Physiol. 33, 465-469.

Walter,J.T.,Dizon, M.-.J., and Khodakhah, K. (2009). The functional equivalence of ascending and parallel fiber inputs in cerebellar computation. J. Neurosci. 29, 8462-8473. 
Wilcox, R. N., Herculano-Houzel, S., and Bower, J.M. (2009). Proportionality of cerebellar Purkinje and granule cells across vertebrate species. Abstr. Soc. Neurosci. 34, 464.2.

Wisden, W., Murray,A.J., McClure, C., and Wulff, P. (2009). Studying cerebellar circuits by remote control of selected neuronal types with GABA(A) receptors. Front. Mol. Neurosci. 2, 29. doi: 10.3389/neuro.02.029.2009.

Womack, M., and Khodakhah, K. (2003). Somatic and dendritic smallconductance calcium-activated potasium channels regulate the output of cerebellar Purkinje cells. J. Neurosci. 23, 2600-2607.

Wulff, P., Shonewille, M., Renzi, M., Viltono, L., and Sassoe-Pognetto, M., (2009). Synaptic inhibition of Purkinje cells mediates consolidation of vistibulo-cerebellar motor learning. Nat. Neurosci. 12, 1042-1051.

Yamazaki, T., and Tanaka, S. (2007).Aspiking network model for passage-of-time representation in the cerebellum. Eur. J. Neurosci. 26, 2279-2292.

Yartsev, M. M., Givon-Mayo, R., Maller, M., and Donchin, O. (2009). Pausing purkinje cells in the cerebellum of the awake cat. Front. Syst. Neurosci. 3, 2. doi: 10.3389/ neuro.06.002.2009.

Conflict of Interest Statement: The authors declare that the research was conducted in the absence of any commercial or financial relationships that could be construed as a potential conflict of interest.

Received: 30 January 2010; paper pending published: 23 March 2010; accepted: 04 July 2010; published online: 27 August 2010.
Citation: Bower JM (2010) Modelfounded explorations of the roles of molecular layer inhibition in regulating Purkinje cell responses in cerebellar cortex: more trouble for the beam hypothesis. Front. Cell. Neurosci. 4:27. doi: 10.3389/ fncel.2010.00027

Copyright (c) 2010 Bower. This is an open-access article subject to an exclusive license agreement between the authors and the Frontiers Research Foundation, which permits unrestricted use, distribution, and reproduction in any medium, provided the original authors and source are credited. 